\title{
Mitochondrial DNA deletion in "identical" twin brothers
}

\author{
E L Blakely, L He, R W Taylor, P F Chinnery, R N Lightowlers, A M Schaefer, D M Turnbull
}

J Med Genet 2004;41:e19 (http://www.jmedgenet.com/cgi/content/full/41/2/e19). doi: 10.1136/jmg.2003.011296

$\mathrm{D}$ efects of mitochondrial DNA (mtDNA) are an important cause of genetic disease in humans. ${ }^{1}$ The defect may take the form of a deletion or point mutation, and clinical features range from severe neonatal illness to mild muscle weakness later in life. ${ }^{2}$ In a recent epidemiology study, single large scale mtDNA deletion disorders represented approximately $25 \%$ of adult patients with mtDNA disease. ${ }^{3}$ The three main syndromes observed in these patients are Pearson's syndrome (PS), a severe systemic illness of childhood associated with sideroblastic anaemia; Kearns-Sayre syndrome (KSS) which is also associated with multiple system involvement; and chronic progressive external ophthalmoplegia (CPEO) in which the predominant clinical problem relates to an eye movement disturbance and ptosis. In both KSS and PS the mtDNA deletion is present in many tissues, ${ }^{4-6}$ whereas in CPEO, the mtDNA deletion is found in muscle but not other tissues. ${ }^{5} 7$

In patients with single large scale mtDNA deletions, it is not established at which stage in development the mtDNA deletion occurs. For the vast majority of cases, there is no family history and as described above, the mtDNA deletion may be limited to a single tissue. Recently, we had the opportunity to study 31 year old twin brothers who were genetically identical in terms of nuclear markers, but one had developed CPEO whereas the other was completely asymptomatic. We hoped that by studying these brothers we might gain further insight into the origin of the mtDNA deletion.

\section{PATIENTS AND METHODS Case reports}

The twin brothers were born 2 months premature, and the first twin (the affected brother) required a forceps delivery. Although no specific problems were documented immediately after birth, the affected twin (patient 1) was noted to have a slightly asymmetric skull (probably related to the delivery) and a slight squint. He was, however, very athletic at school with no evidence of a myopathy. He later developed bilateral ptosis with impaired eye movement bilaterally, but all aspects of eye muscle involvement were worse on the left. Although he had no complaints of muscle weakness, he had a mild proximal myopathy on examination, but no evidence of ataxia or peripheral nerve involvement. The unaffected twin (patient 2) had normal development and no symptoms suggestive of neuromuscular, cardiac, or endocrine disease. He was completely normal on examination. Monozygosity was established using a panel of 16 microsatellite markers (PowerPlexl6, Promega, Southampton, UK) as recommended by the manufacturer.

There was no family history suggestive of neuromuscular or mitochondrial disease particularly on the maternal side of the family, although the mother has never undergone muscle biopsy. She has two additional offspring (now aged 26 and 16 years) by a different partner. Both are clinically unaffected and have not been investigated.

\section{Key points}

- Single mitochondrial DNA (mtDNA) deletions are an important cause of mitochondrial disease. In many patients the mtDNA deletion is sporadic and appears to be limited to skeletal muscle. It is not established at which stage in development the mtDNA deletion occurs.

- We studied identical twin brothers, one of whom presented with chronic progressive external ophthalmoplegia. Southern blot analysis showed that the affected twin harboured high levels of a single 4115 bp mtDNA deletion in his muscle.

- Using sensitive PCR based techniques we show that the identical mtDNA deletion is present in the muscle from the unaffected twin at very low levels, suggesting that the mtDNA deletion was present in the oocyte.

\section{Biochemical and molecular genetic analyses}

Histochemical and biochemical analysis of the muscle biopsies was performed as previously described. ${ }^{8}$ Large scale rearrangements of the mitochondrial genome were screened by Southern blot analysis of total muscle DNA digested with $P v u I I$ and probed with a PCR generated probe (nucleotides 15782-1289) that hybridised to the non-coding control region. Long range PCR was used to amplify across the major arc using primers L6249 (nt 6249-6265) and H16215 (nt 16225-16196). DNA sequencing was performed using M13 tagged PCR primers on an ABI 377 automated DNA sequencer (Applied Biosystems, Warrington, UK). ${ }^{9}$

A real time PCR assay employing SYBR green dye was developed to quantify the level of mtDNA deletion. Pairs of oligonucleotide primers were designed that would selectively amplify only deleted mtDNA (L-11155 forward primer: nt 11155-11173; and H-15384 reverse primer: nt 15384-15366) or wild type mtDNA (L-11155 forward primer and H-11287 reverse primer (nt 11287-11267)). PCR reactions $(20 \mu \mathrm{l}$ volume) were monitored in a Lightcycler ${ }^{\circledR}$ (Roche Diagnostics Ltd, Lewes, UK) using Faststart DNA Master SYBR Greenl. The concentration of $\mathrm{MgCl}_{2}$ was $3 \mathrm{mmol} / \mathrm{l}$ for the amplification of the deleted amplimer and $4 \mathrm{mmol} / \mathrm{l}$ for the amplification of wild type; all primers were at a final concentration of $0.5 \mu \mathrm{mol} / \mathrm{l}$. Following an initial cycle $\left(95^{\circ} \mathrm{C}\right.$ for 10 minutes) to denature the target DNA and to activate the polymerase, samples were subjected to 45 cycles of amplification as follows: $95^{\circ} \mathrm{C}$ for 10 seconds, $64^{\circ} \mathrm{C}$ for 5 seconds and $72^{\circ} \mathrm{C}$ for 10 seconds. Fluorescence was measured at the end of each elongation phase. Following

Abbreviations: CPEO, chronic progressive external ophthalmoplegia; KSS, Kearns-Sayre syndrome; PS, Pearson's syndrome 
quantitative PCR, products were visualised by agarose gel electrophoresis and subjected to melting curve analysis to confirm specificity of the amplicon.

\section{RESULTS}

Histochemical analysis of a left quadriceps muscle biopsy sample from patient 1 showed cytochrome c oxidase deficient fibres $(20 \%)$, many of which had abnormal subsarcolemmal accumulation of succinate dehydrogenase activity (ragged red fibres). Respiratory chain enzyme analysis of muscle mitochondria revealed a decrease in the activity of complex I (25\% of controls) and a partial decrease in the activity of complex IV ( $50 \%$ of controls). The muscle biopsy of patient 2 (also left quadriceps) was completely normal on histochemical and biochemical analysis.

Southern blot analysis revealed a single deleted mtDNA species in patient 1 that was not seen in his brother's muscle DNA. The mtDNA deletion was heteroplasmic, accounting for $66 \%$ of total mtDNA molecules in muscle (fig 1A). The presence of a single mtDNA deletion was confirmed using long range PCR, which amplified a 9967 bp fragment in control muscle mtDNA. Amplification using muscle DNA from patient 1 yielded a single, smaller species, consistent with a single, deleted mtDNA species at high levels. Amplification of his brother's (patient 2) muscle DNA sample appeared to amplify a similar size band, but at barely detectable levels (fig 1B). The presence of low levels of deleted mtDNA in muscle from patient 2 was confirmed by PCR of total muscle DNA across the suspected breakpoint region. Amplification with a pair of M13-tailed primers (L10985: nt 10985-11004; and H15419: nt 15419-15400) yielded a $\sim 350 \mathrm{bp}$ product for both brothers, consistent with an mtDNA deletion of approximately $4.1 \mathrm{~kb}$ (fig lC). No amplification product was detected in the blood from patient 1 using these primers (fig lD).
At this stage, we were concerned about the possibility of contamination of DNA from patient 2. To ensure that this was not the case, DNA was extracted and amplified from another piece of muscle from the unaffected twin in a different laboratory to ensure that no cross contamination of DNA template was possible. Identical results were obtained and the amplified product corresponding to the deleted mtDNA molecule was not detected in the control muscle samples tested at the same time. Sequence analysis of the $\sim 350$ bp PCR products from muscle established that both twins harboured the same mtDNA deletion (4115 bp, nt 11262-15375) with flanking direct sequence (12/13 nucleotides) repeats (fig lE). Low levels of the somatic $4977 \mathrm{bp}$ "common" mtDNA deletion were not detected in the muscle of either twin using a sensitive, competitive three primer, PCR based assay ${ }^{10}$ (data not shown). A duplication of mtDNA was excluded by repeating the Southern blot following digestion of muscle DNA with BamHI (cuts at nt 14528 inside the deleted region) and probed with a $1982 \mathrm{bp}$ fragment (nt 11633-13614). For both patient 1 and control samples only a single species was detected, confirming the absence of any duplicated mtDNA (data not shown).

To calculate the amount of deleted mtDNA in samples from patient 2 we developed a real time, PCR based assay. A standard curve was established in which the wild type mtDNA template (from control muscle) was maintained at a constant level and the deleted mtDNA template (from patient 1) was serially diluted. In all dilutions, values for the wild type mtDNA amplicon generation were within $0.1 \mathrm{Ct}$ units (data not shown). A plot of log fraction deleted mtDNA against $\mathrm{Ct}$ is given in fig 2. Samples of mtDNA from patient 2 and a control subject were amplified after ensuring that there was an identical concentration of mtDNA as used for the standard curve (table 1). The level of mtDNA deletion as a percentage of wild type mtDNA in muscle from patient 2 (unaffected twin) was calculated as $0.08(0.016) \%$.
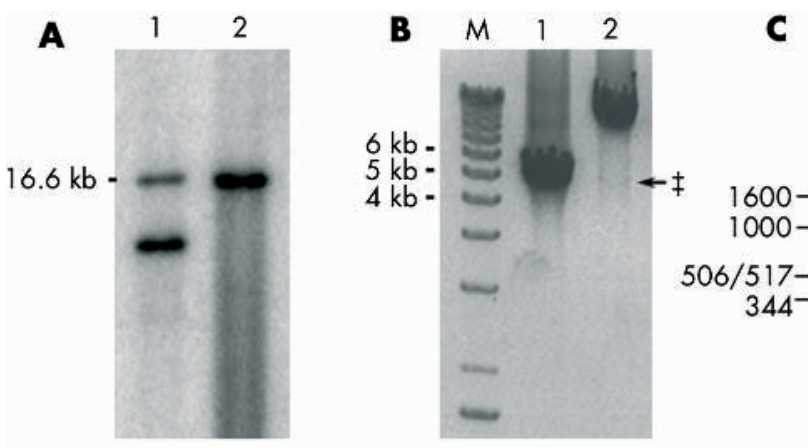

C

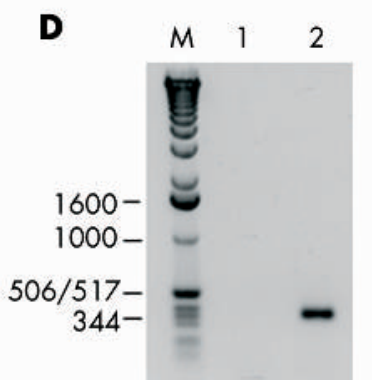

E
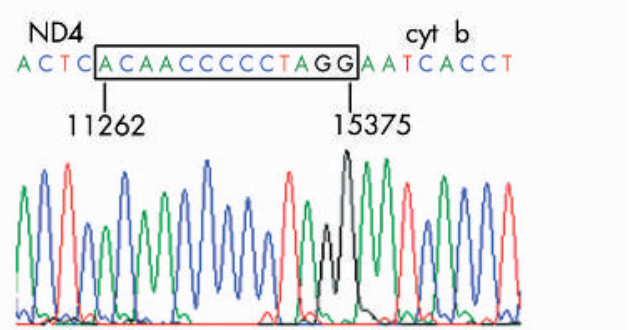

Figure 1 Characterisation of mtDNA deletion. (A) Southern blot analysis of total muscle DNA from patient 1 (lane 1) and patient 2 (lane 2). DNA was digested with Pvull and probed as described in the text. A single major deletion band is only detected in the muscle DNA from patient 1. (B) Long range PCR of muscle DNA from patient 1 (lane 1) and patient 2 (lane 2). The primers amplify a $9.9 \mathrm{~kb}$ product from wild type DNA. For patient 1 , a smaller single species is the only band detected (lane 1), indicative of a single mtDNA deletion. Overexposure of the gel shows a suggestion of a similar size product following amplification of DNA from muscle of patient 2 (lane 2, shown by $\ddagger$ ). (C) Amplification across the mtDNA deletion breakpoint using primers that generate a product of approximately $350 \mathrm{bp}$ in the presence of the mtDNA deletion. Lane 1 represents muscle DNA from patient 1 , lanes 2 and 4 control muscle samples, and lane 3 muscle DNA from patient 2. (D) Amplification across the mtDNA deletion breakpoint, using the same primers as in (C). On this occasion lane 1 is blood DNA (no product detected) whereas lane 2 is muscle DNA from patient 1. (E) Sequence across the mtDNA deletion breakpoint showing the site of the flanking repeat sequence. 


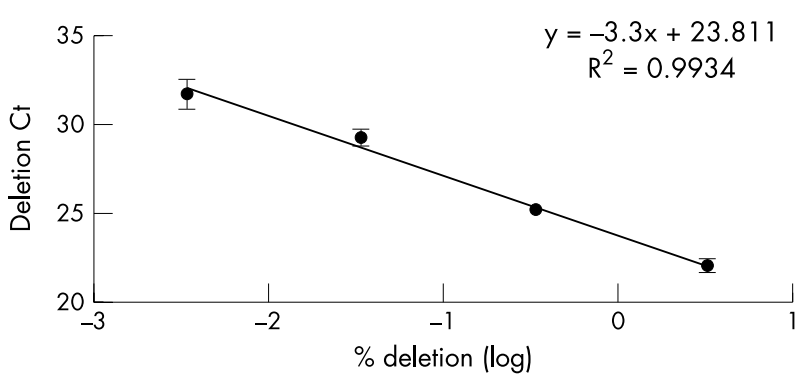

Figure 2 Real time PCR assays detecting deleted mtDNA. Muscle DNA from the affected twin was diluted with control muscle DNA to give the different dilutions of the mtDNA deletion to enable us to construct a standard curve. This showed a good correlation between $\mathrm{Ct}$ and the log of the percentage mtDNA deletion (0.9934). The slope of the line was -3.3 . The values represent the mean (SD) for three separate experiments with each experiment representing three separate PCR reactions. The $\mathrm{Ct}$ value for muscle DNA from patient 2 (unaffected twin) and a control table 1 was compared to the standard curve and the percentage m+DNA deletion was calculated as $0.08(0.016) \%$ for three separate

\section{DISCUSSION}

While these twin brothers are identical in terms of their nuclear genotype, there are differences in the degree of heteroplasmy of the mtDNA deletion in muscle. The affected twin has the characteristic findings of CPEO, both in terms of clinical features and evidence of high levels of mtDNA deletion in muscle but undetectable levels in blood. ${ }^{57}$ In the unaffected twin, there is a detectable level of the identical mtDNA deletion in muscle and thus the mtDNA deletion must have been present before separation into two embryos. We believe the most likely explanation for our findings is that the mtDNA deletion was present in the oocyte. Mitochondrial DNA deletions are thought to arise by slippage during genome replication ${ }^{11}{ }^{12}$ and evidence suggests there is little mtDNA replication during early embryogenesis. ${ }^{13}$ Assuming this is also the case in human embryos, there may well have been no further replication between the oocyte and the separation of the twins (usually between 5-9 days postconception) and thus no opportunity for the mtDNA deletion to develop. Our observations are also entirely compatible with other work suggesting that single large scale mtDNA deletions are rarely maternally transmitted, ${ }^{14}{ }^{15}$, and thus under these circumstances the mtDNA deletion must be within the oocyte. It has previously been shown that mtDNA deletions are present in apparently normal oocytes, although usually at very low levels. ${ }^{16}$ The evidence from our patients is that in apparently sporadic, as well as inherited disease, mtDNA deletions are present in the oocyte rather than developing during embryogenesis.

If we are correct in our assumption that the mtDNA deletion was present in the oocyte, what then is the explanation for the marked differences in the level of deleted mtDNA between muscle tissues in the two brothers? We believe there are at least three possibilities.

- There was uneven distribution of the deleted mtDNA at the time of the development of the two separate embryos. The subsequent high levels in muscle but not blood of the affected twin may then be due to the gradual increase in the level of mutated mtDNA in muscle, ${ }^{17}$ whereas in blood the mutated mtDNA is often lost. ${ }^{18}$

- There was an equal distribution of mutated mtDNA between the embryos but there was uneven segregation of mutated and wild type mtDNA during the development of the affected twin through random genetic drift.

- It has recently been shown that there is nuclear genetic control of mtDNA segregation, ${ }^{19}$ and this may play an

\begin{tabular}{ll}
$\begin{array}{l}\text { Table } 1 \\
\text { mtDNA }\end{array}$ & Real time PCR detection of deleted \\
\hline & Deletion PCR \\
\hline $3.4 \%$ deletion & $22.0(0.21)$ \\
$0.34 \%$ deletion & $25.3(0.17)$ \\
$0.034 \%$ deletion & $29.2(0.31)$ \\
$0.0034 \%$ deletion & $31.7(0.68)$ \\
Patient 2 muscle & $27.5(0.35)$ \\
Control muscle & $32.4(0.71)$ \\
\hline
\end{tabular}

The values represent the mean (SD) for three separate experiments, with each experiment representing three separate PCR reactions.

important role in some of the tissue specific differences in the level of mutated and wild type mtDNA. However, as our patients are identical in terms of their nuclear background, this is less likely.

Interestingly, this study is unlikely to be the first case of twins harbouring a mtDNA rearrangement, as Rowland and colleagues have previously reported monozygotic twins with $\mathrm{KSS}^{20}$ This study, however, was published before it was recognised that single large scale mtDNA deletions were the underlying genetic abnormality in KSS, so there are no published data relating to their molecular defect.

In conclusion, the study has highlighted that even in "identical" twin brothers there can be remarkable differences in the levels of mutated mtDNA in different tissues. More importantly, we believe that these studies support the concept that mtDNA deletions are present in the oocyte before the development of the embryo.

\section{ACKNOWLEDGEMENTS}

We are grateful for continuing support from the Wellcome Trust and Muscular Dystrophy Campaign. We would like to thank Dr A R J Curtis for running the microsatellite markers and Mrs C Hayes for performing biochemical assays.

\section{Authors' affiliations}

E L Blakely, L He, R W Taylor, P F Chinnery, R N Lightowlers,

A M Schaefer, D M Turnbull, Mitochondrial Research Group, School of Neurology, Neurobiology and Psychiatry, The Medical School, University of Newcastle upon Tyne, Newcastle upon Tyne, UK

Correspondence to: Professor D M Turnbull, School of Neurology, Neurobiology and Psychiatry, The Medical School, University of Newcastle upon Tyne, Newcastle upon Tyne NE2 4HH, UK; d.m.turnbull@ncl.ac.uk

\section{REFERENCES}

1 Leonard JV, Schapira AH. Mitochondrial respiratory chain disorders. I: mitochondrial DNA defects, Lancet 2000;355:299-304.

2 McFarland R, Taylor RW, Turnbull DM. The neurology of mitochondrial DNA disease. Lancet Neurol 2002;1:345-51.

3 Chinnery PF, Johnson MA, Wardell TM, Singh-Kler R, Hayes C, Brown DT, Taylor RW, Bindoff LA, Turnbull DM. The epidemiology of pathogenic mitochondrial DNA mutations. Ann Neurol 2000;48:188-93.

4 Zeviani M, Moraes CT, DiMauro S, Nakase H, Bonilla E, Schon EA, Rowland LP. Deletions of mitochondrial DNA in Kearns-Sayre syndrome. Neurology 1988;38:1339-46.

5 Moraes CT, Zeviani M, Schon EA, Hickman RO, Vlcek BW, DiMauro S. Mitochondrial DNA deletions in progressive external ophthalmoplegia and Kearns-Sayre syndrome. N Engl J Med 1989;320:1293-9.

6 Rotig A, Cormier V, Blanche S, Bonnefont JP, Ledeist F, Romero N, Schmitz J, Rustin P, Fischer A, Saudubray JM. Pearson's marrow pancreas syndrome. A multisystem mitochondrial disorder of infancy. J Clin Invest 1990;86:1601-8.

7 Zeviani M, Gellera C, Pannacci M, Uziel G, Prelle A, Servidei S, DiDonato S. Tissue distribution and transmission of mitochondrial DNA deletions in mitochondrial myopathies. Ann Neurol 1990;28:94-7.

8 McFarland R, Clark KM, Morris AA, Taylor RW, Macphail S, Lightowlers RN, Turnbull DM. Multiple neonatal deaths due to a homoplasmic mitochondrial DNA mutation. Nat Genet 2002;30:145-6.

9 Taylor RW, Taylor GA, Durham SE, Turnbull DM. The determination of complete human mitochondrial DNA sequences in single cells: implications for 
the study of somatic mitochondrial DNA point mutations. Nucleic Acids Res 2001;29:e74.

10 Sciacco M, Gasparo-Rippa P, Vu TH, Tanji K, Shanske S, Mendell JR, Schon EA, DiMauro S, Bonilla E. Distribution of wild-type and common deletion forms of mtDNA in normal and respiration-deficient muscle fibers from patients with mitochondrial myopathy. Hum Mol Genet 1994;3:13-19.

11 Schon EA, Rizzuto R, Moraes CT, Nakase H, Zeviani M, DiMauro S. A direct repeat is a hotspot for large-scale deletion of human mitochondrial DNA. Science 1989:244:346-9.

12 Shoffner JM, Lott MT, Voljavec AS, Soueidan SA, Costigan DA, Wallace DC. Spontaneous Kearns-Sayre/chronic external ophthalmoplegia plus syndrome associated with a mitochondrial DNA deletion: a slip-replication model and metabolic therapy. Proc Natl Acad Sci USA 1989;86:7952-6.

13 Piko L, Taylor KD. Amounts of mitochondrial DNA and abundance of some mitochondrial gene transcripts in early mouse embryos. Devel Biol 1987; 123:364-74.

14 Bernes SM, Bacino C, Prezant TR, Pearson MA, Wood TS, Fournier P, FischelGhodsian N. Identical mitochondrial DNA deletion in mother with progressive external ophthalmoplegia and son with Pearson marrow-pancreas syndrome. J Pediatr 1993;123:598-602.
15 Shanske S, Tang Y, Hirano M, Nishigaki Y, Tanji K, Bonilla E, Sue C, Krishna S, Carlo JR, Willner J, Schon EA, DiMauro S. Identical mitochondrial DNA deletion in a woman with ocular myopathy and in her son with Pearson syndrome. Am J Hum Genet 2002;71:679-83.

16 Chen X, Prosser R, Simonetti S, Sadlock J, Jagiello G, Schon EA. Rearranged mitochondrial genomes are present in human oocytes. Am J Hum Genet 1995;57:239-47.

17 Weber K, Wilson JN, Taylor L, Brierley E, Johnson MA, Turnbull DM, Bindoff LA. A new mtDNA mutation showing accumulation with time and restriction to skeletal muscle. Am J Hum Genet 1997;60:373-80.

18 McShane MA, Hammans SR, Sweeney M, Holt IJ, Beattie TJ, Brett EM, Harding AE. Pearson syndrome and mitochondrial encephalomyopathy in a patient with a deletion of m+DNA. Am J Hum Genet 1991;48:39-42.

19 Battersby BJ, Loredo-Osti JC, Shoubridge EA. Nuclear genetic control of mitochondrial DNA segregation. Nat Genet 2003;33:183-6.

20 Rowland LP, Hausmanowa-Petrusewicz I, Bardurska B, Warburton D, NibrojDobosz I, DiMauro S, Pallai M, Johnson WG. Kearns-Sayre syndrome in twins: lethal dominant mutation or acquired disease? Neurology 1988; 38:1399-402. 